\title{
Habitus, dialogismo e resistência no discurso das últimas falantes da língua munduruku do Amazonas
}

\author{
Habitus, dialogism and resistence in the discourse of the last speakers of \\ the munduruku language of Amazonas \\ Ytanajé Coelho CARDOSO* \\ Universidade do Estado do Amazonas (UEA)
}

\begin{abstract}
RESUMO: O objetivo deste trabalho é evidenciar o habitus e o dialogismo inscritos no discurso das últimas falantes da língua munduruku do Amazonas e delinear a maneira pela qual esse movimento enunciativo se projeta como uma proposta de resistência discursiva ante as transformações que vêm ocorrendo no cenário cultural e linguístico dos munduruku do Amazonas. A abordagem se assenta na Etnolinguística, cujo referencial adotado tem como base as propostas de Pierre Bourdieu e de Mikhail Bakhtin. A metodologia utilizada consistiu em análise bibliográfica, análise documental e pesquisa de campo, realizadas em duas etapas, no período de 2015 a 2017.
\end{abstract}

PALAVRAS-CHAVE: Últimas falantes. Língua munduruku. Amazonas. Resistência.

ABSTRACT: The purpose of this work is to evidence the habitus and the dialogism inserted in the speech of the last speakers of the munduruku language of Amazonas, and to delineate the way in which this enunciative movement projects itself as a proposal of discursive resistance to the transformations that have been taking place in the cultural scene of the Munduruku. The approach is based on ethnolinguistics, in prticular on the proposals of Pierre Bourdieu and Mikhail Bakhtin. The methodology used consisted of bibliographic analysis, documentary analysis and field research, carried out in two stages, from 2015 to 2017.

KEYWORDS: Last speakers. Munduruku language. Amazonas. Resistance.

\section{Introdução}

O objetivo deste trabalho é evidenciar o dialogismo inscrito no discurso das últimas falantes da língua munduruku do Amazonas. Além de explicitar essa característica da ação comunicativa, procuramos delinear, por meio da noção de habitus, a maneira pela qual esse movimento enunciativo se projeta como uma proposta de

\footnotetext{
* Mestre em Letras e Artes pelo Programa de Pós-Graduação em Letras e Artes, da Universidade do Estado do Amazonas. Professor substituto da Universidade Federal do Amazonas (UFAM). Professor do Curso de Pedagogia Intercultural Indígena (PARFOR/UEA) e membro do Grupo de Estudos e Pesquisas em Educação Escolar Indígena e Etnografia (UEA).
} 
resistência discursiva ante as transformações que vêm ocorrendo no cenário cultural dos munduruku do Amazonas.

A metodologia utilizada teve como base tanto a pesquisa bibliográfica e de campo quanto a pesquisa de documentos, realizada em duas etapas, no período de 2015 a 2017. Na primeira etapa, em $2015^{1}$, houve a realização de entrevistas com uma das mais antigas anciãs da aldeia Kwatá, Ester Cardoso, ocasião em que foram obtidas diversas narrativas, uma das quais compõe o corpus desta reflexão. Nesse mesmo período, consideramos necessária uma leitura mais detalhada do livro Kwatá-Laranjal: história e reconquista da terra (2002), organizado por Clóvis Oliveira, no qual está proferida a fala de Antônia Cardoso, contadora de narrativas históricas, também da aldeia Kwatá, falecida em 2011, com mais de cem anos. Na segunda etapa, achamos relevante, para efeito desta investigação, a análise dos trabalhos realizados por professores munduruku graduados em Pedagogia Intercultural ${ }^{2}$, pela Universidade do Estado do Amazonas (UEA), em 2014. Nesse sentido, após a leitura dos TCCs, trinta no total, selecionamos apenas um, o de Agnaldo Cardoso Rodrigues, intitulado Resgate da língua Munduruku, defendido no início de 2014. De todos os trabalhos lidos, este foi o único que se debruçou especificamente sobre a importância da língua étnica e de seus falantes, além disso, por ter sido professor no período de sua graduação, seu texto representa fonte importante para a compreensão do dialogismo enquanto resistência, uma vez que constitui um discurso de autoridade no campo educacional. Foi essa autoridade que nos motivou a escolher o texto de Agnaldo, pois seu discurso se coaduna com outro texto que analisaremos: o Projeto Político Pedagógico da Escola Estadual Indígena Ester Caldeira Cardoso, documento legitimador das vozes ancestrais dentro do espaço educacional. A primeira versão deste Projeto foi apresentada em 2015 e até hoje os professores planejam seu aperfeiçoamento. Portanto, o corpus aqui trabalhado

\footnotetext{
1 Nesse período, Luiza Cardoso Munduruku (1920-2016), da geração de Ester e também falante de munduruku, ainda estava viva, no entanto sua saúde bastante frágil não permitiu que fizéssemos entrevistas. Em 2017 faleceu Manduca Rodrigues Munduruku, também da geração de Ester e falante de sua língua étnica. O histórico com mais detalhes desses falantes encontra-se em Cardoso (2017).

2 O Curso de Pedagogia Intercultural (2009-2014), com abrangência em 52 municípios do Amazonas, incluindo a capital Manaus, formou 1.877 (hum mil oitocentos e setenta e sete) professores, sendo 572 (quinhentos e setenta e dois) indígenas e 1.305 (hum mil trezentos e cinco) não indígenas. Nos municípios de Borba e Nova Olinda do Norte (Médio Rio Madeira), onde há maior concentração de munduruku no Amazonas, formaram 30 (trinta) munduruku, sendo dez em Borba e vinte em Nova Olinda, resultando, portanto, em trinta TCCs, abordando temáticas diversas, os quais se encontram arquivados na Reitoria da UEA.A trajetória e os dados do Curso constam em Souza e Bettiol (2016).
} 
compõe-se de duas narrativas, um TCC e um documento importante na esfera da educação escolar munduruku.

Quanto ao referencial teórico, como o próprio título sugere, esta pesquisa baseou-se no conceito de dialogismo proposto por Mikhail Bakhtin. Outro teórico também exerce forte influência aqui, como Pierre Bourdieu, do qual adotamos o conceito de habitus e de poder simbólico, substancial para se entender a configuração discursiva enquanto atitude de resistência sociocultural. Para ajudar a compreender como esses conceitos operam na realidade prática dos discursos, especialmente no corpus deste trabalho, consideramos ainda, o empreendimento reflexivo de Sheila Grillo, a propósito das aproximações teóricas entre Bakhtin e Bourdieu.

Justificamos esta pesquisa pela necessidade de se ampliar os estudos a respeito dos conhecimentos tradicionais e, por conseguinte, históricos desse povo, no âmbito das reflexões etnolinguísticas. Assim, é sabido que, na área da Linguística, já há uma farta literatura sobre a fonética, fonologia, ortografia e sintaxe da língua munduruku: Marjorie Crofts (1973 e 1985), Cristina Comodo (1981), Dioney Moreira Gomes (2006), Gessiane Picanço (2005, 2012), Cássia Braga dos Santos (2013), e, desde a década de 1970, esses campos de investigação vêm se ampliando. Não obstante, só recentemente começaram a aparecer alguns trabalhos mais voltados para uma abordagem sociolinguística e etnolinguística: Cristina Borella e Eneida Santos (2011), Celso Francês Júnior (2014), Ytanajé Cardoso (2017), e também para a área da educação: Adria de Souza (2004), Romy Cabral (2005) e Lucas Furtado (2015).

Releva destacar que esta reflexão é um recorte da nossa dissertação de mestrado, defendida em fevereiro de 2017, cujo objeto da pesquisa foi o discurso dos últimos falantes da língua munduruku do Amazonas. A novidade que apresentamos neste artigo consiste na inclusão do TCC de Agnaldo Cardoso e do Projeto Político Pedagógico da Escola Indígena Ester Cardoso na análise do dialogismo, de maneira a ampliarmos a investigação no interior dos campos da ação comunicativa, nesse caso, os campos político, cultural, educacional e linguístico, trazendo ainda, para dentro do embate teórico, a concepção de "interação discursiva" enquanto realidade fundamental da língua, conforme consta em Marxismo e Filosofia da Linguagem (VOLÓCHINOV, 2017, p. 219). 
O presente artigo está dividido em três seções. A primeira seção procura contextualizar brevemente a presença dos munduruku no cenário das políticas de resistência, com ênfase para algumas ações afirmativas desenvolvidas desde o ano 1999 até os dias atuais. A segunda seção apresenta as ferramentas teóricas que consideramos compatíveis para pensarmos a relação entre língua étnica e resistência no campo discursivo. A terceira seção analisa os enunciados que constituem o corpus, de maneira a compreender sua intencionalidade discursiva e sua força de legitimação dentro do processo de resistência.

\section{História e representação simbólica}

Quando nos referimos à história, estamos falando apenas de alguns eventos de um pequeno recorte no tempo e no espaço, conscientes de que poderíamos incorrer em reducionismos ou generalizações. Assim, em termos de localização, a abrangência deste trabalho se restringe à aldeia Kwatá, situada no rio Canumã, afluente do Médio Rio Madeira. Um dos critérios de escolha se deve ao fato de essa aldeia ser a mais antiga e uma das sedes da Terra Indígena Kwatá-Laranjal/AM, onde, atualmente, encontra-se uma das últimas falantes da língua munduruku do Amazonas ${ }^{3}$. Quanto ao recorte temporal, abordaremos o período que compreende o ano 1999 até os dias atuais. Nesse intervalo de tempo ocorreram significativas mudanças na comunidade e também na relação dos agentes sociais, alvos deste trabalho. Não que não houvesse ocorrido alguma mudança antes disso, ocorreu sim, mas em um ritmo diferente.

Contextualizando a história dos últimos dezenove anos, é relevante fazermos referência ao projeto Kabia'rá, iniciado em 1999, o primeiro elaborado e desenvolvido pela Secretaria de Educação e Qualidade de Ensino (SEDUC/AM), em parceria com os próprios munduruku. Esse projeto surgiu justamente da necessidade de se ampliar a voz indígena perante as políticas de afirmação que se delineavam entre instituições e grupos sociais emergentes. Durante o curso, professores da SEDUC ministravam aulas de Educação Escolar Indígena, enquanto que as anciãs (ou anciãos) da aldeia, últimas

\footnotetext{
${ }^{3}$ Outra falante da geração de Ester é Cecília Munduruku, que mora da aldeia Laranjal, no Rio Mari-Mari. Cecília, com mais de noventa anos de idade, tem muita dificuldade para ouvir e para falar, daí nossa dificuldade de conseguir documentar suas narrativas, em 2016, quando realizamos uma visita à aldeia Laranjal.
} 
falantes da língua munduruku, ministravam aulas de sua língua materna, o munduruku, uma delas era Ester Cardoso, um dos nomes mais citados em Kwatá-Laranjal: história e reconquista da terra (OLIVEIRA et al, 2002), único livro publicado como produto do projeto Kabia'rá. Importa destacar a projeção da voz inscrita na segunda parte do livro, que começa de forma esclarecedora:

Resolvemos convidar Ester Caldeira Cardoso, 77 anos, esposa do seu Nunito Cardoso, já falecido, e dona Antônia Cardoso Munduruku, 98 anos, moradoras da aldeia Kwata, para irem um dia na nossa sala de aula e participarem das discussões juntamente com os professores e lideranças indígenas (...).

Queríamos que elas falassem sobre os acontecimentos daquela época, da vida delas, da vida de antigamente. (OLIVEIRA et al, 2002, p. 37).

Ester Cardoso faz parte de uma geração de anciãs que nasceu falando somente o munduruku, vindo a aprender o português um pouco antes da adolescência, assim como Antônia Cardoso, por volta das primeiras décadas do século passado. São as principais fontes de informação quando se refere à história dos munduruku. Em realizações de eventos comemorativos ou reuniões, Ester normalmente participa na condição de autoridade ancestral. Ester Cardoso foi, ainda, a principal colaboradora do trabalho que Cássia Braga dos Santos desenvolveu a respeito do quadro fonético-fonológico da língua munduruku do Madeira (SANTOS, 2013) ${ }^{4}$. Quanto a Antônia Cardoso (19062011), restaram poucos registros, tanto escritos quanto audiovisuais, o que dificultou uma análise mais profunda de seu discurso. Existe apenas um vídeo ${ }^{5}$ em que Antônia aparece discursando na língua munduruku, em pouco menos de um minuto.

A voz que emerge nesse pequeno fragmento do livro acima citado é de professoras e professores da SEDUC e também da própria comunidade, os quais perceberam a necessidade de se estabelecer a interlocução com os conhecimentos ancestrais no âmbito do curso, este caracterizado pela abordagem de educação escolar indígena, e não somente educação indígena, como durante séculos ocorrera. Aqui podemos notar e refletir o papel exercido pelas anciãs da comunidade, isto é, foram solicitadas a discursar para outro grupo, de maneira a contribuir no processo enunciativo entre as vozes que ecoam no universo comunicativo indígena. Isso era comum e ainda o

\footnotetext{
4 É perceptível, na leitura do texto, que a referência à Ester Cardoso seja mais intensa, isso porque há muito mais registro dela do que de Antônia Cardoso.

${ }^{5}$ Disponível em:https://www.youtube.com/watch?v=cGMbnQe-tac. Acesso em: 02 abr. 2018.
} 
é hoje, embora saibamos que as relações econômicas e sociais emergentes estão mudando as formas de produção e reprodução cultural dentro da estrutura social dos povos indígenas. Mas o que mais nos interessa no momento é o fato de haver uma valorização do discurso ancestral no seio desse processo de reconfiguração educacional, o que impulsiona o campo acadêmico a traduzir essa oralidade ancestral e decodificá-la em linguagem escrita.

Podemos dizer, portanto, que há uma força centrípeta atuando sobre os enunciados advindos desses agentes, cujo papel social é fundamental para entendermos como esse processo ocorre. O conceito de capital simbólico nos ajuda a explicarmos esse fenômeno dentro das relações de produção cultural inscritas na história recente dos munduruku. Assim, para Bourdieu (2004, p. 166), “o capital simbólico é um crédito, é o poder atribuído àqueles que obtiveram reconhecimento suficiente para ter condição de impor o reconhecimento". À luz dessa concepção, entendemos que o reconhecimento ao discurso das anciãs se deve ao próprio anseio de querer ser ouvido e, já adentrando na seara teórica de Bakhtin (2003, p. 280), à atividade responsiva do destinatário.

Nesse sentido, fazendo um levantamento da autoridade discursiva na aldeia Kwatá, elencamos alguns fatos relevantes quanto ao papel desses agentes. Por exemplo, é comum pesquisadores, sobretudo da área de humanas, procurarem os mais velhos ${ }^{6}$ da aldeia para coletar histórias, como foi o caso de Romy Cabral (2005), Cassia Braga (2013), Daniel Scopel (2013), Raquel Dias Scopel (2014), apenas para citar os mais recentes e aqueles com quem tivemos contato direto. Todos eles, além do contato que tiveram, citam algumas das anciãs da aldeia Kwatá, sendo que Ester Cardoso é citada em todos esses referidos trabalhos. Quanto aos eventos culturais da comunidade, em abril de 2015, no contexto do Festival Cultural Munduruku e Sateré Mawé (FECMS), festa tradicional do povo, os organizadores do evento reuniram duas anciãs e um ancião falantes da língua munduruku - dentre as quais Ester Cardoso - no centro da quadra onde se realizavam as apresentações culturais, a fim de que pudessem conversar na língua materna, o munduruku ${ }^{7}$, e a aconselhar o povo, sobretudo os jovens. Os outros

\footnotetext{
${ }^{6}$ É muito comum, dentro do campo cultural e educacional, os munduruku utilizarem esse termo como sinônimo de sabedoria e referência histórica. É nesse sentido que adotamos essa palavra.

7 Apesar de a língua materna dos munduruku do Amazonas ser o português, a língua materna dos anciãos aqui citados é o munduruku, pois foi sua língua primeira. Vale dizer que, em termos históricos, o povo
} 
dois anciãos eram Manduca Munduruku e Luiza Cardoso Munduruku, os quais ainda eram vivos em abril de 2015. Outra falante do munduruku bastante conhecida, mas que faleceu em 2011, foi Antônia Cardoso Munduruku, também considerada uma das últimas falantes da língua munduruku. Antônia foi uma das protagonistas do projeto Kabia'rá (1999-2004), assim como o foi Ester Cardoso. Essas duas anciãs foram fundamentais no processo de conscientização para a revitalização da língua étnica de seu povo, inclusive atuando como professoras no Projeto Kabia'rá. Foi essa atuação que nos motivou a escolher Antônia e Ester como fontes dos enunciados que serão analisados. Embora Antônia tenha falecido em 2011, suas ações ainda ecoam na memória do povo munduruku, mais particularmente na memória dos professores formados pelo projeto Kabia'rá, como é o caso de Agnaldo Rodrigues, formado em Pedagogia Intercultural e autor do TCC que selecionamos para analisar. Embora em seu texto Agnaldo não mencione diretamente o nome das últimas falantes, ele utiliza ora o termo "falante" ora o termo "ancião".

Para compreender melhor a autoridade de Antônia, é oportuno destacar um vídeo produzido em 2001, por ocasião do processo de demarcação da Terra Indígena Kwatá-Laranjal. O vídeo, que será descrito com mais detalhes na terceira seção, tem quinze minutos de duração e apresenta uma imagem breve e rara de Antônia contando a história de seu povo na língua munduruku. Em relação à Ester, a documentação em áudio e vídeo é farta e de melhor qualidade, como podemos observar no documentário intitulado Os últimos falantes da língua munduruku do Amazonas: os profetas da ancestralidade, postado no YouTube em 29 de julho de $2017^{8}$. Essa documentação audiovisual é um registro importante para a contextualização do discurso dessas anciãs.

Apresentamos a história particular de alguns agentes que exercem um papel de destaque na sociedade indígena, e esse papel caracteriza-se pelo poder simbólico outorgado aos detentores do discurso ancestral, nesse caso, às anciãs. Isto é, elas são as legítimas representantes dos conhecimentos tradicionais, materializados na complexa teia da ação comunicativa, onde há regularidades e um conjunto de estratégias envolvidas. Consideramos o conceito de estratégia, à luz de Bourdieu, bastante

munduruku, de maneira geral, entende que a língua materna é o munduruku, tanto que se empreende hoje uma possível revitalização linguística.

${ }^{8}$ Disponível em: $<$ https://www.youtube.com/watch?v=UbGZbrxRQjM\&t=2179s $>$. Acesso em: 09 jan. 2019. 
pertinente à compreensão do discurso ancestral enquanto representação simbólica, já que revela o projeto enunciativo desenhado na ação comunicativa. Retomaremos esse conceito mais adiante quando fizermos a análise do corpus.

\section{Habitus e dialogismo}

Bourdieu (1996) nos traz grande contribuição quando desenvolve o conceito de habitus dentro do campo teórico da Sociologia, podendo ser, se necessário, reivindicado por outras disciplinas, como a Linguística. Nesse caso, trazemos, para dentro dos estudos da linguagem, a perspectiva de habitus bourdieusiano, isso por considerarmos sua grande relevância enquanto dispositivo que nos ajudará a compreender a maneira pela qual o dialogismo bakhtiniano, fundamento analítico central de nosso trabalho, está instituído na trama da ação comunicativa, isto é, no discurso das últimas falantes da língua munduruku do Amazonas.

O conceito de habitus constitui uma das bases da sociologia de Bourdieu, privilegiando o estudo social da linguagem, que abrange tanto a língua enquanto sistema de signos no sentido estruturalista quanto a língua enquanto capital social, cultural e histórico, inserido dentro da dinâmica do mercado linguístico. Nesse sentido, Bourdieu afirma que os discursos são não apenas signos a serem decifrados e compreendidos, "são também signos de riqueza a serem avaliados, apreciados, e signos de autoridade a serem acreditados e obedecidos” (BOURDIEU, 1996, p. 53). Essa percepção da língua abre caminho para entendermos as relações estabelecidas entre os agentes situados na história e sua produção enunciativa, cujo movimento histórico de afirmação discursiva foi estruturando formas de dizer e de compreender que se tornaram regulares dentro, por exemplo, do campo educacional. Destarte, consoante Bourdieu (2004, p. 98),

O habitus, como sistema de disposições para a prática, é um fundamento objetivo de condutas regulares, logo, da regularidade das condutas, e, se é possível prever as práticas (neste caso, a sanção associada a uma determinada transgressão) ${ }^{9}$, é porque o habitus faz com que os agentes que o possuem comportem-se de uma determinada maneira em determinadas circunstâncias.

\footnotetext{
9 Quando Bourdieu diz "neste caso", está se referindo à análise das práticas da sociedade Cabila, povo que vive no norte da Argélia. Seu primeiro livro publicado foi a respeito desse grupo social (ver obra Sociologia da Argélia, de 1958). No nosso caso, como já dissemos, estamos analisando o discurso das anciãs da aldeia Kwatá enquanto discurso de resistência.
} 
Podemos entender, com efeito, que essas disposições se vinculam estrategicamente às maneiras e às circunstâncias de se produzir e reproduzir um discurso, cuja regularidade ${ }^{10}$ está materializada nas condutas incorporadas ao longo do processo de ressignificação social, incitada pela necessidade de se adaptar a novos contextos. Daí recorrermos à noção de estratégia, que é "o instrumento de uma ruptura com o ponto de vista objetivista e com a ação sem agente que o estruturalismo supõe [...] Ela é produto do senso prático como sentido do jogo, de um jogo social particular" (BOURDIEU, 2004, p. 81). A estratégia constitui, a nosso ver, tanto um mecanismo de perpetuação de uma prática quanto uma ferramenta de resistência simbólica no cerne do embate discursivo que ocorre nos campos sociais, como é o caso do campo educacional entre os munduruku, cujas recentes condições de produção têm levado a instituição escolar a introduzir novas ferramentas de aprendizagem dos conhecimentos tradicionais. Isto é, se por um lado os munduruku aprendiam com as histórias contadas diretamente pelos anciãos e anciãs, por meio da oralidade, agora passam a ler essas mesmas histórias nos mais variados gêneros textuais escritos. Nessa linha de reflexão, Cardoso (2018, p.

15) propõe os textos ressignificáveis ao currículo escolar munduruku, muitos dos quais trazem as vozes das anciãs. Um exemplo desse tipo de texto é uma monografia intitulada Munduruku: uma história de luta (MORAES DE OLIVEIRA, 1991). Além da dedicatória aos anciãos munduruku, a autora (1991, p. 39) relata o papel atribuído à Ester e à Antônia:

\begin{abstract}
A sociedade MUNDURUKU cansada e envergonhada ao ver que a riqueza de seu povo estava próxima de ser banida completamente de suas vidas, uniram-se reivindicando dos professores o ensino da língua materna em sala de aula, lutando pela educação diferenciada, bilíngue. Assim sendo, os velhos: Da. Ester, Da. Antônia e Sr. Maximino passaram a ser professores oficiais de oralidade, ensinando as crianças a falarem a língua MUNDURUKU. Os resultados são positivos, muitas crianças e adolescentes já conseguem construir frases na língua nativa. Essa luta é de toda comunidade que visa obter o resgate da sua cultura.
\end{abstract}

Muitas dessas crianças citadas que receberam ensinamentos de Ester e de Antônia são, atualmente, professores indígenas, os quais acabam por promover o discurso de resistência que foi sendo incorporado enquanto habitus e perpetuado por práticas sociais e textuais emergentes: eventos culturais, reuniões escolares, produção de

\footnotetext{
10 De acordo com Bourdieu, não podemos confundir regularidade com regra, está sendo a palavra de ordem do estruturalismo, aquela "produto agregado de ações individuais" (idem, p. 82). Não estamos dizendo que o sociólogo francês descarta o conceito de regra advinda do estruturalismo, ele o reorienta.
} 
poemas, de músicas ${ }^{11}$, de livros, de trabalhos acadêmicos, de documentários e dos mais variados tipos de narrativas. O que interessa, doravante, é entendermos de que forma esse conjunto de propensões incorporado se esboça em meio ao dialogismo estabelecido entre as vozes ancestrais e as vozes atuais envolvidas no campo discursivo.

A propósito do dialogismo, por ser um conceito bastante amplo no quadro teórico de Mikhail Bakhtin (2003, p. 300), nos restringiremos à utilização de apenas uma de suas vertentes, àquela que José Fiorin ${ }^{12}$ enumera como o primeiro conceito de dialogismo (2008, p. 30), cujo fundamento pode ser resumido na ideia de que todo enunciado constitui-se a partir de outros. Estamos nos referindo, assim, ao dialogismo constitutivo, o qual Bakhtin (2003, p. 300) nos esclarece dizendo:

Em realidade, repetimos, todo enunciado, além do seu objeto, sempre responde (no sentido amplo da palavra) de uma forma ou de outra aos enunciados que o antecederam. O falante não é um Adão, e por isso o próprio objeto do seu discurso se torna inevitavelmente um palco de encontro com opiniões de interlocutores imediatos (na conversa ou na discussão sobre algum acontecimento do dia-a-dia) ou com pontos de vista, visões de mundo, correntes, teorias, etc. (no campo da comunicação cultural).

Tendo em vista que os enunciados se manifestam por meio dos gêneros do discurso inscritos num certo campo ${ }^{13}$, situamos o nosso objeto dentro do campo político, cultural, educacional e, sobretudo, linguístico, onde as vozes se constroem impulsionadas por relações de força material e simbólica. Essa relação ocorre, no interior do campo, tanto pelo diálogo com enunciados anteriores quanto pelos enunciados posteriores. $\mathrm{O}$ que nos interessa é entender que o diálogo está presente no contexto de comunicação dos agentes, cada qual sendo orientado por um conjunto de disposições incorporado, o habitus, produto e, ao mesmo tempo, gerador das práticas sociais, encadeadas pela competência adaptativa do agente na rede semiótica do contexto.

Vale ressaltar que o contexto referido aqui é o momento de transformação no campo cultural e político da aldeia Kwatá, especificamente dos discursos de resistência

\footnotetext{
${ }^{11}$ Todos os anos os munduruku preparam seus poemas e músicas para apresentaram no Festival Cultural Munduruku, no mês de abril. Os vencedores ganham prêmios, normalmente em dinheiro.

12 Fiorin desenvolve a diferença entre o dialogismo constitutivo e o dialogismo composicional em Introdução ao pensamento de Bakhtin (2008). Adotaremos apenas o primeiro.

${ }^{13}$ Sheila Grillo já demonstrou a compatibilidade entre a noção de campo de Bourdieu e do Círculo de Bakhtin. Segundo ela, "as duas obras concebem o campo como um aspecto social capaz de refratar, traduzir ou transformar as demandas externas, sobretudo da base sócio-econômica comum." (2005, p. 176).
} 
emergentes: o discurso da ancestralidade. Por discurso da ancestralidade, entendemos os enunciados que se constituem pelas vozes das anciãs e pelas vozes que se constituem a partir dos enunciados engendrados pelas próprias anciãs, agentes da comunicação.

Com efeito, afirmamos em nossa empreitada analítica, a importância conceitual do habitus bourdiesiano e do dialogismo bakhtiniano, uma vez que nos oferece alternativas para a compreensão das práticas comunicativas de determinados campos. Ambos os teóricos desenvolvem suas reflexões à luz da realidade concreta dos eventos e levando em consideração o papel dos agentes tanto na rede das relações sociais quanto na arquitetura das ações comunicativas, o que antes era ignorado por outras correntes teóricas. E essa perspectiva implica uma abertura para a concepção proposta por Volóchinov, segundo o qual "a interação discursiva é a realidade fundamental da língua" (2017, p. 219). Sendo a interação discursiva de natureza essencialmente dialógica, as vozes ancestrais se inserem nesse processo como uma fonte de interação sócio-histórica, instaurando práticas de interação enunciativa no interior dos campos sociodiscursivos, legitimadas e perpetuadas pela força do habitus discursivo, dentro do qual a língua étnica, especificamente, funciona como capital a ser valorizado, sobretudo no interior do campo educacional, para o qual as produções acadêmicas estão sendo reorientadas.

\section{Análise do corpus}

Como já havíamos dito, o corpus de nosso trabalho constitui-se de duas narrativas, um TCC e um documento importante, para os munduruku, na área da educação. A primeira narrativa é um relato de Antônia Cardoso que está no livro Kwatá-Laranjal: uma história de reconquista, cuja temática se assenta no uso da língua munduruku. A segunda narrativa é um excerto de uma entrevista que realizamos na aldeia Kwatá, com Ester Cardoso, a qual também falou sobre o ensino de sua língua materna. Em relação ao TCC, de Agnaldo Cardoso Rodrigues, o conteúdo se refere ao processo de revitalização da língua munduruku e sua importância para esse povo indígena. No que concerne ao documento importante, trata-se do Projeto Político-Pedagógico da Escola Estadual Ester Cardoso Munduruku, localizada aldeia Kwatá. 
Resolvemos apresentar o enunciado de Antônia Cardoso por ser um dos poucos que podem ser encontrados em registros escritos, já que a comunicação era estabelecida, quase que totalmente, pela oralidade ${ }^{14}$. Sendo assim, segue a fala de Antônia Cardoso, contida na obra Kwatá-Laranjal: uma história de reconquista, organizada pelo professor Clóvis de Oliveira.

\begin{abstract}
Naquela época o padre ${ }^{15}$ era o professor dos índios. Foram os padres que ensinaram português para os índios. Minha mãe falava [...] ainda me lembro bem, pra gente ter muito cuidado. Ela dizia que um dia os brancos iam chegar na aldeia e que iam nos ensinar a falar o português e a gente ia perder a linguagem. Quando isso acontecesse, a gente ia perder a cultura [...] Agora meu filho [...] está preocupado com a linguagem. Quer aprender a falar a linguagem de novo. Mas quando eu chamava sua atenção quando ele era pequeno, não queria obedecer não. Não queria aprender a falar a linguagem, tinha vergonha. Agora taí. (2002, p. 38).
\end{abstract}

Esse enunciado, proferido em português, reflete não só a história dos munduruku, mas também sua realidade social e linguística. Percebemos que Antônia cita sua mãe, que certamente deve ter vivido em meados do século XIX. Também faz referência a seu filho ${ }^{16}$, o qual, na época de vigência do projeto Kabia'rá, era uma das lideranças indígenas. Isto é, temos um discurso que retoma o passado e que se projeta para o futuro. Percebamos que no momento da enunciação o receptor não era apenas seu filho, mas todos os agentes presentes na ocasião da aula. Num plano mais extensivo, podemos dizer que o enunciado procurou alcançar aquilo que Bakhtin chama de supra destinatário, já que o "autor do enunciado propõe, com maior ou menor consciência, um supradestinatário superior (o terceiro), cuja compreensão responsiva absolutamente justa ele pressupõe quer na distância metafísica, quer no distante tempo histórico"

14 Ester Cardoso afirma que em sua infância ninguém sabia escrever ou ler. Somente quando grupos religiosos começaram a adentrar o território indígena, nas primeiras décadas do século passado, é que os munduruku começaram a aprender a língua portuguesa, e, por conseguinte, aprender a ler e escrever. É bem verdade que os registros históricos escritos, até então encontrados, não dão conta de explicar de forma clara como se deu esse processo de colonização por meio das ordens religiosas.

${ }^{15}$ São bastante escassos os registros que comprovem a maneira pela qual os munduruku do Amazonas foram perdendo a língua étnica, o que sabemos é que Antônia cita o padre, sem dar maiores detalhes. Algum tempo depois, por volta da década de 1930, Ester Cardoso relata a história de Amélia, professora que obrigava os munduruku a falarem somente a língua portuguesa (CARDOSO, 2017, p. 33, 78,79, 123, $124,131,132,133)$. Mesmo tendo esses relatos orais de Ester, fica difícil afirmar de forma detalhada o principal motivo que levou os munduruku a deixarem de falar sua língua étnica. Mas é possível afirmar que tanto o padre citado por Antônia quanto a professora Amélia citada por Ester influenciaram no processo de estigmatização da língua munduruku, levando, não raras vezes, muitos munduruku a sentirem vergonha de se afirmarem como indígenas.

${ }^{16} \mathrm{O}$ filho aqui referido é Agapito, inclusive citado na dissertação da professora Cássia Braga dos Santos (2013, p. 20). 
(2003, p. 333). Essa concepção discursiva se coaduna inteiramente com o diálogo entre as vozes pressupostas no enunciado de Antônia. Sintetizando, seu enunciado pressupõe, assim, outros enunciados.

É interessante destacar, ainda, que em 2001, por ocasião do processo de demarcação da Terra Indígena Kwatá-Laranjal, mesmo período do Projeto Kabia’rá, Antônia foi entrevistada por um funcionário da Fundação Nacional do Índio. Nessa entrevista, postada no YouTube ${ }^{17}$ em 20 de abril de 2012, a anciã conta a história de seu povo na língua munduruku:

\begin{abstract}
ijopoceka (esta é nossa aldeia), koapat (primeira), boce kuopop (está ali), oceka'bukbuk (nossa velha aldeia), boce wi (de lá), boce ku (ali) kayawebe (em Kayawe)/ ajojoyũ' ũm'ũm osodop (viviam nossos ancestrais)/ Ibocedak yobog̃ osodop (lá era grande também, era)/ ocebadipyũ (nossos parentes) ajojoyũ (nossos avôs/ancestrais)/ ipiboyawaso (cortou Boyawaso), ipiotakat (cortou a terra), boywasoipiotakat (boyawaso cortou a terra) ${ }^{18}$.
\end{abstract}

Como podemos observar no enunciado, escrito em munduruku e com uma tradução em português, Antônia narra determinados eventos que ocorreram no período em que os munduruku chegaram onde hoje é a aldeia Kwatá. Quando Antônia se refere à “oceka'bukbuk”, está mostrando, inclusive por meio de gestos, que aparecem no vídeo, onde foi o primeiro local que os munduruku chamaram de Kwatá, isto é, do outro lado do igarapé. Em "ajojoyũ", Antônia dialoga com a memória de seus ancestrais e introduz um termo ambíguo: boyawaso. Ambíguo porque ela pode tanto estar se referindo a uma figura mitológica que também faz parte do imaginário munduruku ou pode estar se referindo à narrativa segundo a qual existe uma cobra grande que mora próximo da aldeia Kwatá e que vez ou outra ela aparece para se alimentar de outros animais grandes.

Agora adentraremos no enunciado de Ester Cardoso, anciã detentora do capital linguístico e cultural, legitimada pelo próprio povo munduruku a discursar nos momentos em que se quer fazer ouvir a voz da experiência e da sabedoria. $\mathrm{O}$ teor do enunciado carrega a percepção de uma autoridade, sobretudo, simbólica, e nos ajuda a compreender essa representação enquanto habitus e enquanto resistência discursiva.

\footnotetext{
${ }^{17}$ Disponível em:<https://www.youtube.com/watch?v=cGMbnQe-tac>. Acesso em: 09 jan. 2019. A fala de Antônia vai de $4 \min 46 \mathrm{~s}$ a $5 \mathrm{~min} 32 \mathrm{~s}$. Este é o único registro audiovisual de que se tem conhecimento. Apesar dos nossos esforços para encontrar outros, não conseguimos.

${ }^{18}$ Esta tradução se deve a Honésio Dace Munduruku, que atendeu à nossa solicitação e não hesitou em colaborar com este trabalho.
} 
Logo, perguntada sobre qual sua visão a respeito do futuro da língua munduruku, Ester Cardoso responde:

To dizendo, eu tenho tanta fé em deus que essas criança vão aprender, gente grande mesmo também, gente velho, e os professor que eu andei, andei ajudando eles pra aprender a falar linguagem lá pelo Laranjal, Mari-Mari. Mas eu to dizendo que eles não conversam, num conversam ${ }^{19}$.

Caberia uma pergunta aqui: por que o discurso das anciãs se desenvolve no sentido da valorização cultural e linguística do povo indígena? Nossa análise nos leva a entender que é por conta da resistência surgida ao longo do processo de contradições históricas e sociais que caracterizou o cenário do contato entre povos indígenas e não indígenas no Brasil. Tal cenário encontra-se explicitado em Luciano (2006, p. 19, 20, 40, 57, 163, 205). Essas práticas de resistência acabaram por desembocar na emergência de um habitus enquanto estratégia, enquanto capital cultural propenso a ir na contramão (ou não) ${ }^{20}$ do discurso dominante. Este discurso dominante foi muito marcado, por sua natureza violenta e impositiva, por volta da década de 1930, quando uma professora, de nome Amélia, obrigava os munduruku a falar somente o português, como consta no relato de Ester:

\begin{abstract}
Ela queria que as criança aprendessem logo a falar português, mas eles não sabiam falar português. Ela queria por força que elas aprendessem falar português logo, mas como que elas iam aprender? Ela tinha que ter paciência [...] que ela ensinava as criança, começava a bater nas criança, mandava pelar (raspar a cabeça), assim, o rapaz, jovem assim, moça mesmo.
\end{abstract}

Os enunciados de Ester revelam estreita ligação com o enunciado de Antônia, já que ambas consideram importante a utilização da língua étnica e ambas se referem ao processo de imposição da língua portuguesa entre os munduruku em tempos passados. Quando Ester se refere aos professores, isto é, aos professores indígenas que foram ajudados por ela, não apenas está se referindo a um evento passado, mas está evocando, também, a ação responsiva deles enquanto supra destinatário, ou seja, o grupo dos professores, o qual herdará o discurso de Ester. Esses valores incorporados pelo discurso ancestral é o habitus, manifestado como estratégia de resistência no centro

${ }^{19}$ Em grande parte das entrevistas que foram realizadas, Ester manifestou-se predominantemente em português, ela falava em munduruku apenas quando era instigada. Nesse trecho específico em que ela trata do processo de perda linguística, sua fala foi proferida em português.

${ }^{20}$ Se vai na contramão ou não, isso depende do ponto de vista tanto das instituições sociais, de grupos, ou das pessoas individualmente, quanto da posição teórica adotada. Não entraremos nessa discussão, o que nos interessa é a materialidade do discurso de resistência, elaborado e permeado de poder simbólico. 
dessa conjuntura dialógica. Resistência, inclusive, contra o discurso de negação de Amélia, que chegava a impor severos castigos para que as crianças aprendessem, deforma rápida, o português.

Conhecendo essa realidade de perda linguística, um movimento de reflexão que procurava denunciar as perdas históricas passou a fazer parte do imaginário munduruku, resultando em algumas políticas de promoção cultural, dentro da qual se inclui a revitalização linguística. E como já afirmamos, o projeto Kabia'rá foi um marco importante para o desenvolvimento dessas políticas, já que daí saíram professores para atuarem nas escolas, cujo ensino procurava enfatizar o estudo da língua munduruku. Muitos desses professores, interessados com a ideia de uma formação continuada, não só do projeto Kabia'rá, mas aqueles que posteriormente terminaram o ensino médio, procuraram ingressar em cursos de nível superior, como foi o caso do autor do TCC que selecionamos para analisar.

Apresentamos, agora, o fragmento do TCC de Agnaldo Cardoso Rodrigues, de maneira a entendermos de que forma esses enunciados se unificam ${ }^{21}$ numa proposta de resistência sociocultural e linguística. Segue, então, o texto:

As memórias que vem nos refletir é a língua materna Munduruku que com passar do tempo foi sendo parada de ser falada, tanto tempo que tínhamos nossos avôs e avós pessoas mesmo munduruku que falavam bem nossa língua e nós perdemos esses antigos guerreiros que já faleceram. (2014, p. $5)^{22}$.

O autor do enunciado afirma o munduruku como língua materna, concebendo-a no sentido histórico, e, além disso, cita os "avôs e avós". Novamente visualizamos o dialogismo que norteia a atividade enunciativa. Dessa vez, este enunciado já é uma resposta àqueles de Antônia e Ester, uma resposta cujo caráter se configura pela responsabilidade e conclusibilidade do enunciado. Responsabilidade porque Agnaldo exerceu seu ato responsivo ante os enunciados das anciãs, e conclusibilidade por haver a possibilidade da alternância dos atores no discurso. Conforme Bakhtin, "a

\footnotetext{
${ }^{21}$ Se unificam no sentido de estabelecer uma unidade de coerência discursiva, sem que esse discurso seja isolado, isto é, produzido somente pelas anciãs. Aqui a unidade significa justamente a diversidade de enunciados produzidos por uma diversidade de agentes.

${ }^{2} \mathrm{O}$ que nos interessa aqui é o caráter simbólico que esse enunciado representa e não sua estruturação intratextual ou o referencial terminológico adotado, não nos cabendo, portanto, lançar juízo sobre esses aspectos.
} 
conclusibilidade $^{23}$ do enunciado é uma espécie de aspecto interno da alternância dos sujeitos do discurso; essa alternância pode ocorrer precisamente porque o falante disse tudo (ou escreveu) tudo o que quis dizer em dado momento ou sob dadas condições" (2003, p. 280).

No que diz respeito às condições de constituição do enunciado, o situamos no interior das relações simbólicas, materializadas no habitus enquanto estratégia de resistência. A estratégia, segundo Bourdieu "é produto do senso prático como sentido do jogo, de um jogo social particular, historicamente definido, que se adquire desde a infância, participando das atividades sociais" (2004, p. 81). Nessa perspectiva, a estratégia bourdiesiana se coaduna substancialmente com a realidade prática de Agnaldo Cardoso, já que este, desde a infância, mora na aldeia Kwatá, compartilhou (e ainda compartilha) dos mesmos valores de suas avós, incorporou o sistema de disposições, isto é, os modos de percepção, o habitus, o qual pode se adequar às necessidades do jogo social e discursivo.

Além da preocupação com a perda das anciãs e anciãos e tudo o que eles possam representar, Agnaldo também propõe alternativas para não deixar que a língua seja esquecida completamente. É nesse sentido que ele descreve o seu trabalho de valorização da língua étnica em turmas do terceiro ano do ensino fundamental, realizado ao longo das disciplinas de Estágio Supervisionado I, II e III, na Escola Municipal Kasopta (RODRIGUES, 2014, p. 11):

\begin{abstract}
A pesquisa vem resgatar a língua mundurucu ${ }^{24}$ nas escolas municipais na turma do $3^{\circ}$ ano do ensino fundamental nas aldeias, com objetivo de enriquecer a língua materna com objetivo de cada aluno aprender falar à linguagem que a nossa identidade principal do povo mundurucu da aldeia Kwata Rio Canumã com essa pesquisa acredito que vamos ter o conhecimento da nossa língua materna mundurucu. Este projeto de pesquisa vai fortalecer mais a nossa linguagem que está quase se perdendo, então este projeto vem trazer para nos conhecer a língua materna. ${ }^{25}$
\end{abstract}

Nesse enunciado, podemos visualizar a atitude linguística positiva por parte do discurso de Agnaldo e sua materialização no espaço escolar. E quando o então professor

\footnotetext{
${ }^{23}$ Bakhtin estabelece alguns critérios de conclusibilidade do enunciado, dentre os quais o mais importante é justamente a ação responsiva, o que pressupõe a alternância dos agentes. (2003, p. 180).

${ }^{24}$ Agnaldo utiliza um modelo ortográfico antigo, mas palavra munduruku, com a letra k, já é consenso.

${ }^{25}$ A dificuldade de escrever em português formal está relacionada com a aprendizagem tardia e precária na educação básica. Agnaldo é monolíngue em português, daí que essa dificuldade não pode ser atribuída a um possível bilinguismo, dificuldade essa que é comum entre os munduruku do Pará, onde a grande maioria tem o munduruku como L1 e o português com L2.
} 
diz que "com essa pesquisa acredito que vamos ter o conhecimento da nossa língua materna mundurucu", está sugerindo, conforme a análise dialógica, não apenas a revitalização da língua munduruku, mas também a reflexão sobre a história da própria língua, pois a escola, por estar em um momento de construção do seu currículo, ainda carece de reflexões mais profundas sobre o processo de perda linguística. Ainda conforme sua atitude linguística, seu discurso se junta aos discursos de outros professores, com especial atenção para os recém graduados em Licenciatura Intercultural Indígena Munduruku, pela Universidade do Federal do Amazonas. Sobre o discurso desses professores, Francês Júnior (2014, p. 73) já demonstrou, por meio de pesquisa qualitativa e quantitativa, que há uma unidade discursiva, representada pela atitude linguística dos professores, no sentido de se promover o estudo da língua munduruku dentro das comunidades. E um desses discursos que se une ao de Agnaldo é o da professora Rosana Brasil (FRANCÊS JÚNIOR, p. 100), ao afirmar que "já, aí mesmo no kwatá... A minha avó Antônia, minha avó Esther ia lá ensinava as crianças, ensinava nós na escola. Contava história”. Além desse diálogo com as vozes ancestrais, Rosana também responde a eles com ações que se materializam no plano artístico, como é o caso do poema escrito e declamado em 2010, na aldeia Kwatá. Esse poema, escrito em português e traduzido para o munduruku com a ajuda dos professores munduruku do Pará, tem cinco estrofes. Destacamos apenas a última estrofe do poema intitulado $O$ festival mundurucu em fortalecimento da nossa cultura, de maneira a ilustrarmos a atitude linguística de Rosana, manifestado em forma de poema:

Figura 1 - Última estrofe do poema $O$ festival munduruku em fortalecimento da nossa cultura

ESTOU EXÉRCITANDO A VOCÉS

UM POUCO DO QUE APRENDE

FALANDO NA LÍNGUA INDIGENA

A poESIA Que ESCREVI
ON IKUKUN EIWEJU

AJO WETAIBIN YOPITIAM

WAIOM JEKA WẼN' WẼN

JOP POESIA O GU BAPAPAI

Fonte: Professora indígena Rosana Brasil

Quando Rosana diz que está exercitando o que aprendeu, está respondendo às vozes ancestrais, assim como o está, também, Agnaldo. Ambos estão de acordo que é preciso orientar o imaginário cultural munduruku sobre a importância da língua para o povo, ambos estão de acordo em fortalecer a rede dialógica entre o passado e o presente, 
projetando um possível futuro. Esses professores não deixam de contribuir com as inúmeras vozes de resistência sociocultural e linguística, e quando se trata do campo educacional, suas vozes se amplificam ainda mais, já que a tarefa de planejamento linguístico para o futuro cabe, sobretudo, a eles enquanto professores. Nesse sentido, já podemos ver resultados concretos dessas reflexões, como por exemplo, a construção da primeira versão do Projeto Político Pedagógico da Escola Estadual Ester Cardoso Munduruku (PPP), documento importante para a educação escolar munduruku, que traz em seu texto a preocupação com a manutenção da língua munduruku e que também dialoga com as vozes ancestrais.

O PPP, que leva o nome de uma das últimas falantes da língua munduruku do Amazonas, é resultado de reflexões que se ampliam de maneira mais intensa no âmbito do Projeto Kabia'ra, uma extensão do Programa Pirayawara, coordenado pela Gerência de Educação Escolar Indígena do Estado do Amazonas. Esse documento não deixa de fazer parte daquilo que Bourdieu (1996, p. 97) chama de ritos de instituição, ou ritos de consagração. Isto é, o PPP é um texto legítimo da área da educação escolar que consagra o discurso de resistência, perpetuando um habitus, portanto, no interior do campo educacional. Assim, o próprio documento enuncia (2015, p. 4):

\begin{abstract}
Nós professores indígenas Munduruku, juntamente com as lideranças, agentes de saúde, alunos, anciãos, organizações indígenas e famílias em geral da Terra Indígena Kwatá-Laranjal, apresentamos o Projeto Político Pedagógico diferenciado para a Escola Estadual Indígena Ester Caldeira Cardoso Munduruku situada na aldeia Kwatá/rio Canumã, município de Borba, estado do Amazonas.

Este documento resulta não somente de processos de discussões, análises e reflexões ocorridas durante a execução do Projeto PIRAYAWARA ${ }^{26}$, Programa de Formação de Professores Indígenas, no município de Borba, como também de experiências e práticas pedagógicas desenvolvidas em nossas salas de aula.
\end{abstract}

Ao evocar os anciãos, o PPP acaba por afirmar a autoridade dos ancestrais, legitimando suas vozes e consagrando-as na história do povo munduruku do Amazonas por meio de um documento que orientará a educação das próximas gerações, cuja estrutura tem como base a Matriz Curricular Intercultural de Referência para o Ensino Fundamental e Ensino Médio para as Escolas Indígenas do Estado do Amazonas, estabelecida pela Resolução $n^{\circ}$ 02/2014. Seguindo esta Matriz, o PPP abrange as quatro

\footnotetext{
${ }^{26}$ Nesse caso, Pirayawara é o programa de formação continuada. Dentro do Programa há vários projetos, cada qual nomeado conforme o acordo do povo para o qual é direcionada a ação.
} 
áreas do conhecimento: Linguagens, Matemática, Ciências da Natureza, Ciências Humanas. Abrange ainda, uma área complementar: Formas Próprias de Educar: Oralidade, Trabalho, Lazer e Expressões Culturais. No Ensino Fundamental essas áreas se dividem em oito componentes curriculares, já no Ensino Médio as áreas estão divididas em quatorze componentes curriculares.

Interessa destacar a ênfase dada, no PPP, à área de Linguagens, em que tanto no Ensino Fundamental quanto no Ensino Médio há o componente curricular Línguas Indígenas, em todas as séries, totalizando uma carga horária de 1800 horas apenas para esse componente, sendo 1440 horas ao longo do Ensino Fundamental e 360 horas ao longo do Ensino Médio. Isso indica que a Escola Ester Cardoso Munduruku terá o grande desafio de consolidar uma política didático-pedagógica para o ensino desse componente curricular como segunda língua, uma vez que, no Amazonas, ninguém mais fala o munduruku, com exceção de Ester Cardoso e Cecília Munduruku, ambas com quase cem anos. Ester Cardoso, por exemplo, faz cem anos em 22 de março de 2019.

O fato de a Escola Ester Cardoso se tornar autônoma e possuir um Projeto Político Pedagógico com ênfase para a língua e cultura munduruku já é um significativo passo para fortalecer as políticas de resistências no espaço educacional. Resta, daqui por diante, propor conteúdos que forneçam ao estudante ferramentas para refletir sobre sua história, sua língua, tua terra, enfim, sobre sua identidade, conforme reivindicação do discurso ancestral. Resta, também, propor cursos de aperfeiçoamento para os próprios professores, de maneira que, desse diálogo estabelecido com as vozes dos anciãos e anciãs, resulte um conjunto de ações para a prática escolar.

Por ser a versão inicial, o PPP ainda está em construção. Falta elaborar, por exemplo, o texto que trata das áreas do conhecimento e dos seus componentes curriculares, conforme os conteúdos compatíveis com a proposta de valorização identitária e linguística. Nesse sentido, ao considerar "importante a aprendizagem e a preservação da língua materna munduruku” (PPP, 2015, p. 12), o documento acaba por reunir as vozes tanto dos ancestrais quanto dos professores em uma proposta de resistência não só no plano do abstrato, mas também no plano da prática, e o Projeto Político Pedagógico da Escola Ester Cardoso Munduruku é um exemplo concreto dessa política de resistência, resultado do diálogo de diversas vozes, tanto as do passado 
quanto as do presente. Fato importante é que esse documento não deixa de constituir uma extensão do discurso ancestral, cuja memória, daqui em diante, deverá ser repassada não mais por meio da oralidade anciã, mas sim por meio dos livros que já foram escritos, que estão em processo de escrita e por aqueles que ainda serão escritos.

O PPP, portanto, é a última etapa desta breve análise que lançamos sobre o dialogismo inscrito no discurso das últimas falantes da língua munduruku do Amazonas, que começou destacando os enunciados de Antônia, seguido dos enunciados de Ester, de Agnaldo, de Rosana e concluindo com o PPP.

Retomando o enunciado originário da mãe de Antônia, em que projeta a perda da língua étnica como consequência da imposição da cultura europeia, podemos traçar uma genealogia discursiva que abrange quatro gerações: a geração da mãe de Antônia, a geração de Antônia e de Ester, a geração do filho de Antônia, Agapito ${ }^{27}$, e a geração de Agnaldo e de Rosana, sobrinho e sobrinha de Agapito. Discursos que atravessam uma história de luta pelo direito de manifestar sua cultura. Podemos dizer que é o discurso direcionando a história do povo munduruku. É o discurso afirmando uma cultura negada há séculos, em que cada palavra ou cada enunciado dialoga com a história de resistência, vislumbrando possíveis caminhos em direção a uma relação cultural mais condescendente dentro da estrutura social brasileira. A palavra, portanto, reflete não só a história de negação, mas também projeta um futuro de afirmação, o que nos leva a conceber, na esteira de Volóchinov, que "nos destinos da palavra estão os destinos da sociedade falante" (2017, p. 319).

\section{Considerações finais}

Procuramos mostrar os contornos da ação comunicativa das últimas falantes da língua munduruku do Amazonas. Para tanto, adotamos o conceito de habitus e de dialogismo. Este, proposto pelo filósofo russo Mikhail Bakhtin, aquele, pelo sociólogo francês Pierre Bourdieu. Nossa análise se assentou numa reflexão etnolinguística, cuja contribuição de ferramentas sociológicas nos possibilitou ampliarmos o diálogo com outras disciplinas, ampliando também, nossa percepção diante dos objetos. Nesse

\footnotetext{
${ }^{27}$ Destacamos o nome, pois ele também é citado no livro como filho de Antônia.
} 
sentido, é bastante oportuno evocar as circunspectas palavras de Bourdieu quando diz que "enquanto ignorarem o limite que é constitutivo de sua ciência, os linguistas não têm alternativa senão buscar desesperadamente na língua o que está inscrito nas relações sociais nas quais ela funciona” (1996, p. 24). O que sociólogo francês está sugerindo é que olhemos além do nosso próprio espaço de concentração teórico. É verdade que estamos inclinados a concordar com Bourdieu.

O resultado dessa aliança teórica nos fez compreender, ainda que preliminarmente, o intrincado cenário social, cultual e discursivo onde circulam os enunciados. Certamente nos apresentou alternativas de analisar um objeto sob diferentes aspectos, e também suscitou novas indagações que deverão ser desenvolvidas e aprofundadas em outros trabalhos: sabendo que as anciãs munduruku estão morrendo, como a escola está se organizando para receber esses discursos de resistência? De que maneira o currículo está sendo sistematizado no sentido de promover a memória ancestral? Que metodologia deverá ser aplicada em sala para que o componente curricular Língua Indígena possa ser ministrado com êxito? Se há, quais ferramentas estão sendo utilizadas? Esses questionamentos surgiram ao longo dessa reflexão, uma vez que nossa preocupação também se volta para a manutenção e melhoramento das condições socioculturais desse povo no espaço escolar e também fora dele, pois acreditamos que devemos, até por uma relação de respeito para com o grupo pesquisado, deixar nossa contribuição enquanto pesquisadores.

Nesse sentido, o estudo do dialogismo, por meio do habitus, revelou não só algumas nuances da interação discursiva entre enunciados instaurados na história dos munduruku, mas também promoveu discussões que podem resultar em propostas para o aperfeiçoamento do campo educacional, cuja reivindicação vem do próprio povo. Cabe a nós, e àqueles que se interessam pelo desenvolvimento da educação escolar munduruku, a continuação dessa incursão no reino das palavras, dos enunciados e dos discursos. 


\section{REFERÊNCIAS}

BAKTHIN, Mikhail M. Estética da criação verbal. Trad. Paulo Bezerra. $4^{\circ}$ ed. São Paulo: Martins Fontes, 2003.

BORELlA, Cristina de Cássia; Santos, Eneida Alice. Língua Mundurukú na Terra Indígena Kwatá-Laranjal: a espera do outro. In: Congresso Internacional de Estudos Linguísticos e Literários na Amazônia, 2011, Belém.Anais do III CIELLA, Belém: UFPA. Disponível em: http://www.etnolinguistica.org/local--files/artigo:borella-santos2011/borella_santos_2011_espera.pdf. Acesso em: 28 mar 2018.

BOURDIEU, Pierre. Coisas ditas. São Paulo: Brasiliense, 2004.

Economia das trocas linguísticas: o que falar quer dizer. São Paulo: Editora da Universidade de São Paulo, 1996.

CABRAL, Romy Guimarães. Modos de educar: vida Munduruku e relação gente e natureza na Aldeia Kwatá. Dissertação (Mestrado em Educação) - Faculdade de Educação, Universidade Federal do Amazonas, 2005.

CARDOSO, Ytanajé Coelho. O currículo de linguagens na educação escolar munduruku: estratégias de planejamento. Revista Amazônida:Revista do Programa de Pós-Graduação em Educação da Universidade Federal do Amazonas, v. 2, n. 2, p. 04-

-30, mar. 2018.2 Disponível em: <http://periodicos.ufam.edu.br/amazonida/article/view/4342>. Acesso em: 18 jan. 2019.

Os últimos falantes da língua munduruku do Amazonas:habitus, dialogismo e invenção cultural no campo discursivo. Dissertação (Mestrado em Letras e Artes) Programa de Pós-Graduação em Letras e Artes, Universidade do Estado do Amazonas, 2017.

COMODO, Cristina Helena Rohwedder. Concordência em mundurukú. Dissertação (Mestrado em Linguística) - Instituto de Estudos da Linguagem, Universidade Estadual de Campinas, Campinas, 1981.

CROFTS, Marjorie. Aspectos da língua Munduruku. Brasília: SIL, 1985.

Gramática Munduruku. Brasília: SIL, 1973.

DIAS-SCOPEL, Raquel Paiva. A cosmopolítica da gestação, parto e pós-parto:práticas de autoatenção e processo de medicalização entre os índios Munduruku. Tese (Doutorado em Antropologia Social) - Programa de Pós-Graduação em Antropologia Social. Florianópolis: UFSC, 2014.

FIORIN, José Luiz. Introdução ao pensamento de Bakhtin. São Paulo: Ática, 2008.

FRANCÊS JÚNIOR, Celso. Atitude linguística e a revitalização da língua mundurukú:observações preliminares. Dissertação (Mestrado em Linguística) Programa de Pós-Graduação em Letras, Universidade Federal do Pará, Pará, 2014. 
FURTADO, Lucas Antunes. A prática pedagógica intercultural do/a professor/a munduruku. Dissertação (Mestrado em Educação) - Faculdade de Educação, Universidade Federal do Amazonas, 2015.

GOMES, Dioney Moreira. Estudo morfológico e sintático da língua Mundurukú (Tupí). Tese (Doutorado em Linguística) - Departamento de Linguística, Línguas Clássicas e Vernáculas, Universidade de Brasília, 2006.

GRILLO, Sheila Vieira de Camargo. A noção de campo nas obras de Bourdieu e do Círculo de Bakhtin: suas implicações para a teorização dos gêneros do discurso. Revista da ANPOLL. São Paulo, v. 19, p. 151-184, 2005. Disponível em: http://www.anpoll.org.br/revista/index.php/revista/article/view/461/470. Acesso em: 28 mar. 2018.

LUCIANO, Gersen dos Santos. O Índio Brasileiro:o que você precisa saber sobre os povos indígenas no Brasil hoje. LACED/Museu Nacional, Brasília, 2006.

MORAES DE OLIVEIRA, Luciene. Munduruku: história de luta. Monografia. Curso de Especialização em Etnologia Indígena Brasileira. Universidade Católica de Goiás. Manaus, 1991.

OLIVEIRA, Clóvis Fernando Palmeira (Org). Kwatá-Laranjal:Uma História de Reconquista da Terra. SEDUC-AM, Manaus, 2002.

PICANÇO, Gessiane Lobato. Introdução ao Mundurukú: fonética, fonologia e ortografia. Cadernos de Etnolingüística, Goiânia, v.1, 62 p, 2012. Disponível em: http://www.etnolinguistica.org/mono:3. Acesso em: 28 mar 2018.

Mundurukú: phonetics, phonology, synchrony, diachrony. Tese (DoutoradoemLinguística), The Faculty of Graduate Studies, University of British Columbia, 2005.

PROJETO POLÍTICO PEDAGÓGICO MUNDURUKU. Organização dos/as Professores/as Munduruku do Amazonas. Borba: Aldeia Kwatá, 2015.

RODRIGUES, Agnaldo Cardoso. Resgate da Lingua Munduruku. 2014. 15 f. Trabalho de Conclusão de Curso. Pedagogia Intercultural. Universidade do Estado do Amazonas, Borba, 2014.

SANTOS, Cássia Alessandra Braga dos. Aspectos da fonologia do Munduruku do Madeira. Dissertação (Mestrado em Linguística) - Programa de Pós-Graduação em Linguística, Universidade de Brasília, Brasília, 2013.

SCOPEL, Daniel. Uma Etnografia sobre a Pluralidade de Modelos de Atenção à Saúde entre os Índios Munduruku na Terra Indígena Kwatá Laranjal, Borba, Amazonas:Práticas de Autoatenção, Xamanismo e Biomedicina. Tese (Doutorado em Antropologia Social) - Programa de Pós-Graduação em Antropologia Social, Universidade Federal de Santa Catarina, Florianópolis, 2013. 
SOUZA, Adria Duarte de. Identidade, Educação Escolar Indígena e Bilingüismo na Aldeia Munduruku. Dissertação (Mestrado em Educação) - Faculdade de Educação, Universidade Federal do Amazonas, 2004.

SOUZA, Adria Duarte de; BETTIOL, Célia Aparecida (Orgs). Unindo pessoas por meio dos rios: a experiência do PROIND no ensino presencial mediado por tecnologia. Manaus: UEA Edições, 2016.

VOLÓCHINOV, Valentin. Marxismo e filosofia da linguagem: problemas fundamentais do método sociológico na ciência da linguagem. Trad. Sheila Grillo e EkaterinaVólkova Américo. São Paulo: Editora 34, 2017. 